\title{
Efficacy of Brief Lifestyle Change in conjunction with Dental Care (Brief-LCDC) Programs on glycemic and periodontal status among DM patients
}

\author{
Saruta Saengtipbovorn \\ Dental Health Division, Health Center 54, Bangkok, Thailand
}

\begin{abstract}
Purpose - A global trend of type 2 diabetes prevalence is rising. Preventing and managing of systemic and dental complications is crucial to decrease negative effects on glycemic control. The purpose of this paper is to estimate the efficacy of Brief Lifestyle Change in conjunction with Dental Care (Brief-LCDC) Programs to decrease glycemic level and improve periodontal status in patients with type 2 diabetes.

Design/methodology/approach - Health Center 54 conducted randomized controlled trial among 192 patients (96 intervention and 96 control) from February to August 2018. Group education for lifestyle modification, individual oral hygiene instruction and lifestyle counseling by motivational interviewing was provided to the intervention group at baseline. Motivation of lifestyle modification every month by multimedia was also provided to the intervention group. The usual program was provided to the control group. At baseline and a six-month follow-up, glycemic level and periodontal status were assessed from participants. Data were analyzed by descriptive statistic, $t$-test, $\chi^{2}$ test, Fisher's exact test, Repeated measure ANOVA and multiple linear regression.

Findings - Glycemic level and periodontal status were lower in the intervention group than the control group at the sixth-month followed up with statistical significances. Glycemic level and periodontal status had negatively correlated to intervention group with statistically significant.

Originality/value - Brief-LCDC Program which incorporated lifestyle modification and oral health care had efficacious to decrease glycemic level and improve periodontal status in patients with type 2 diabetes. Early prevention program by Brief-LCDC Program is crucial to prevent dental complications.
\end{abstract}

Keywords Type 2 diabetes, Glycemic level, Lifestyle modification, Oral health care, Periodontal status

Paper type Research paper

\section{Introduction}

Diabetes mellitus (DM) is a disorder of carbohydrate metabolism and a significantly serious public health problem[1]. The rapid increase in DM and other non-communicable diseases are a global health challenge, particularly in developing and underdeveloped countries[2]. In Thailand also, DM is an urgent public health concern[3]. The fifth Thai National Health Examination Survey of 2014 found the prevalence of DM increasing, especially amongst the younger age group[4]. The prevalence of DM amongst the Thai population aged above 15 years increased from 6.9 percent in 2009 to 8.9 percent in 2014[4]. Moreover, the prevalence of DM amongst the Thai population aged 30-44 years increased from 3.4 percent in 2009 to 5.4 percent in 2014[4].

(c) Saruta Saengtipbovorn. Published in Journal of Health Research. Published by Emerald Publishing Limited. This article is published under the Creative Commons Attribution (CC BY 4.0) licence. Anyone may reproduce, distribute, translate and create derivative works of this article (for both commercial and non-commercial purposes), subject to full attribution to the original publication and authors. The full terms of this licence may be seen at http://creativecommons.org/licences/by/4.0/legalcode

Conflicts of interest: the author reports no conflict of interest in the present study. 
JHR

33,3

Macrovascular and microvascular complications are types of diabetes complications[1]. A macrovascular complication is a cardiovascular disease which causes stroke, heart attack and decreased blood flow to the legs[1]. Microvascular complications include retinopathy that causes deterioration to the eyes, nephropathy which deteriorates the kidney, neuropathy which deteriorates the nerves, delays in wound healing and also periodontal disease which deteriorates the gingiva[1].

Periodontal disease is the infection of the structure around the teeth involving the periodontium. Systemic inflammation from periodontal disease is one of the complications of type 2 diabetes[1]. The bidirectional negative effects come from both DM and periodontal disease[1, 5]. Uncontrolled diabetes (HbAlc $\geqslant 7$ percent) influences the periodontal status and inflammatory cytokine from periodontal disease also influences glycemic levels[1]. The seventh Thai National Oral Health Survey in 2012 found that 85.9, 89.0 and 91.8 percent of the population aged 35-55 years, 60-74 years and above 80 years, respectively, had periodontal diseases[6].

In 2018, the Health Department of the Bangkok Metropolitan Administration found 25.0 percent of the Bangkok population was at risk of developing DM. Furthermore, only 47.0 percent of registered diabetic patients from 68 health centers under the Health Department had records of controlled glycemic levels (HbA1c $<7$ percent)[7].

Earlier screenings for prevention of diabetes complications have included eye examinations, blood testing, foot screening, kidney examination, lipid profile testing, screening of cardiovascular risk and oral health examinations[7]. Management of type 2 diabetes was proposed by The American Diabetes Association (ADA) and the European Association for the Study of Diabetes (EASD) who recommended a patient-centered approach[8]. Furthermore, it was advised that lifestyle modification and combination therapy should be accomplished by patient-centered diabetes management[8]. Lifestyle modification is a change of long-term habits, such as eating or physical activity, and maintaining new behavior patterns for months or years and can be used to treat a range of diseases, including DM[1]. Motivational interviewing (MI) guides patients to investigate and deal with their reservations and uncertainties through goal-oriented, patient-centered counseling to encourage behavior modification[9]. MI is useful for health-related behaviors, such as diet and exercise, medication compliance, substance abuse and periodontal health[9, 10].

At present, diabetic complications are prevented and controlled by programs or interventions for lifestyle modification consisting of nursing-related lifestyle modification[11], lifestyle modification by dietary counseling and exercise[12], and increased self-care behavior and medication compliance[13]. Oral complications (periodontal disease) have been prevented and improved by periodontal programs or interventions consisting of oral hygiene instruction and periodontal treatment[14-18]. However, lifestyle modifications or periodontal programs alone are not always sufficient to avoid oral complications because of the bidirectional negative effects of periodontal disease and glycemic levels[5].

Another method is the incorporated approach to chronic disease prevention to overcome the social inequalities of patients[19]. In this context, DM and periodontal disease prevention are incorporated by modifying risk factors which affect both DM and periodontal disease. For example, the lifestyle change plus a dental care (LCDC) program, which combined lifestyle modification and oral health care intervention by using the common risk factor approach and MI was applied to aging DM patients. After the LCDC program, the elderly patients had better knowledge, attitude, and decreased blood sugar levels, and an improved periodontal status[20, 21]. However, the LCDC program was only applied to aging DM patients and was time-consuming (20 min of MI per visit) and required increased health personnel to deal with the rise in DM patients. However, due to the increasing prevalence of DM amongst a younger age group (30-44 years)[4] and the increasingly prevalent progression of periodontal disease from DM[15, 16], the prevention 
programs for aging DM patients might be too little too late to avoid oral complications, and a similar program to support and reduce the exacerbation of the problem from an earlier age was deemed advisable. Therefore, incorporating the brief lifestyle modification and oral health care program for every age group by the common risk factor approach and MI are considered essential to prevent oral complications. The Brief Lifestyle Change in conjunction with Dental Care (Brief-LCDC) Program is one such program that can be applied to all age groups.

The elderly have the benefit of their experience which supports their ability to learn from this program[22]. Therefore, the Brief-LCDC Program adjusted the contents of the LCDC program due to the different learning abilities between aging and non-aging patients. Group education combines a variety of age groups who benefited from shared and varied experiences between ages. Furthermore, individual lifestyle counseling that emphasizes differentiated instruction based on individual differences focus on the patient's ability, interest and readiness had responded to the different learning ability between aging and non-aging patients[23]. Additionally, a combined age-group Brief-LCDC Program could save motivational instruction from $20 \mathrm{~min}$ (on the LCDC program) to 10 min for MI per visit. Also, when patients learn more about their levels of ability, interest, and readiness, the frequency of MI could be decreased from every three months (LCDC program) to every six months.

The present study estimated the efficacy of the Brief-LCDC Program to decrease the glycemic levels and improve the periodontal status of patients, as well as estimated the correlation between the Brief-LCDC Program and the glycemic level and the periodontal status in patients with type 2 diabetes.

\section{Methods}

This research was conducted in Health Center 54 located in Bangkok, Thailand, and included a double-blind randomized controlled trial from February to August 2018. Patients diagnosed with type 2 diabetes including $\mathrm{HbAlc} \geqslant 7$ percent[24], and who had at least 16 natural teeth (appropriate for examining plaque index $(\mathrm{PI})$ and gingival index $(\mathrm{GI})$ ) were included in the study. Patients who had severe systemic diseases or complications, including hematologic disease, liver disease, and kidney disease, severe chronic periodontitis, or who could not communicate or speak the Thai language, or patients who did not agree to participate were excluded. The study protocol was approved by the Bangkok Metropolitan Administration Ethics Committee for Human Research (S001h/61). All participants signed informed consent forms before data collection. The sample size was calculated from a previous study[20] and included 87 participants in each group by achieving 80 power at a 5 percent significant level. The Clinical Attachment loss (CAL) of intervention and control groups were 2.97 and 3.44 (effect size: 0.47 ), respectively, and the pooled variance was 1.23[20]. The entire sample size was increased to 192 participants (96 per group) due to the 10 percent increase for attrition and refusal.

The DM clinic in Health Center 54 is held on Tuesdays and Thursdays. The research team randomly assigned the Tuesday clinic for the intervention and the Thursday clinic for the control groups. A total of 96 participants in each group were selected by the research team using systematic sampling techniques. The selected number was from the number of total patients in the DM clinic divided by the calculated sample size. A total of 14 participants were excluded; 6 from the intervention group because 1 participant had a kidney disease, 2 participants had severe chronic periodontitis and 3 participants did not agree to participate, and 8 from the control group because 2 participants had severe chronic periodontitis, 1 participant had kidney disease and the other 5 participants did not agree to participate. Therefore, at baseline, 192 participants (96 per group) finally participated in the present study.
Brief-LCDC

Programs 
JHR

33,3

\section{Training of interviewers}

The interviewers were trained up to the required standard by attending a day-long meeting. Training in MI for lifestyle modification and oral health care was provided. Instructional media and teaching techniques were also provided by experts in diabetes, dentistry and education to the nurse and dental assistant during a day-long training session. The teaching techniques were adjusted from the LCDC program because the Brief-LCDC Program can be adapted to every age group. Group education concentrated on sharing experiences between elderly and younger patients. Individual lifestyle counseling concentrated on differentiated instruction.

\section{Intervention}

The Brief Lifestyle Change plus Dental Care (Brief-LCDC) Program is adapted from the LCDC program[20, 21] and is based on a health belief model, social cognitive theory and cognitive-behavioral theory. The Brief-LCDC Program also uses the common risk factor approach[19] that incorporates the prevention and management of DM and periodontal disease through lifestyle modification and oral health care by inter-professional collaboration from physicians, nurses, dentists, and dental assistants and individual lifestyle counseling by MI. The contents of the Brief-LCDC Program were adjusted from the LCDC program in content and teaching techniques to make it appropriate for all age groups. The Brief-LCDC Program was decreased from $20 \mathrm{~min}$ (as in the LCDC program) to $10 \mathrm{~min}$ for MI per visit due to the age of participants and also decreased in the frequency of MI visits from three months to every six months.

In order to develop the necessary instructional media for group education and multimedia for the motivation of lifestyle modification and oral health care, a focus group discussion was held by collecting ideas from a physician, a nurse, a dentist, a dental assistant and a representative of a patient with type 2 diabetes. Three experts in education, diabetes and dentistry validated the instructional media and multimedia. The focus group discussion group also pretested the instructional media and multimedia and three focus groups, each with six type 2 diabetic patients who received service in Health Center 42 were also pretested.

A nurse with prior teaching experience provided a 20-min multimedia session for all participants on group education for lifestyle modification and oral health at baseline. The contents of the group education for lifestyle modification consisted of etiology, signs and symptoms, complications of diabetes, the prevention and management of diabetes complications, the association between type 2 diabetes and oral complications, and oral health care. The same nurse, who provided group education and was already trained in MI, also provided patientcentered individual lifestyle counseling, which was consistent with the contents of the group education using MI. Afterwards, participants chose a goal for their lifestyle modification and their oral health care. The goals covered the topics of dietary modification, exercise, self-care behavior, emotional and dental care. A dental assistant who was already trained in oral health education provided individual oral hygiene instruction for tooth brushing techniques, which emphasized flossing techniques and the use of a proxa brush to prevent periodontal disease.

Individual lifestyle counseling by $\mathrm{MI}$ and individual oral hygiene instruction were repeated after six months. Additionally, booster sessions to promote lifestyle modification and oral health care were provided to the participants every month via a multimedia platform. Moreover, the physician and nurse revised each patient's goals for lifestyle modification and oral health care every month.

\section{Control group}

The regular health center program consisted of visiting the physician every month, receiving group education for diabetes from a nurse, pharmacist, and dental personnel, checking fasting plasma glucose (FPG) and receiving diabetic medicine. 


\section{Outcome measures}

Face-to-face interviews by questionnaire, blood sample testing and dental examinations were performed in both groups at baseline and at the six-month follow-up using the double-blind technique.
Brief-LCDC

Programs

\section{Dental examination}

The dentist examined a full-mouth PI[25] and the GI[25] including four sites (buccal, lingual, mesial and distal). Probing depth (PD)[25] and gingival recession[25] were also examined on all maxillary and mandibular teeth. All dental examinations were performed by the standard manual periodontal probe (PCPUNC 15; Hu-Fridy ${ }^{\circledR}$, Chicago, IL, USA). CAL was calculated from the PD plus gingival recession[25]. Two consecutive examinations of 20 participants ( $24 \mathrm{~h}$ apart) were performed before beginning the study to get the intra-examiner reliability. Two dentists including one periodontal expert examined the periodontal status of five patients with type 2 diabetes to obtain inter-examiner reliability. The Cohen's $\kappa$ was 0.85 .

Blood sample testing; nurses collected the venous blood samples. FPG and Glycated hemoglobin $(\mathrm{HbA1c})$ was assayed by using the glucose oxidase method and immunoassay method respectively at the Bangkok Metropolitan Administration laboratory.

A questionnaire was used to find baseline characteristics of the participants including gender, age, educational level, body mass index, health insurance, duration of diabetes and smoking status.

\section{Statistical analyses}

In order to compare baseline differences between groups, a descriptive statistic, $t$-test, $\chi^{2}$ test and Fisher's exact test were undertaken. Repeated measure ANOVA was tested for the change in outcomes across time. The differences in outcome changes were assessed by time-by-group interaction effects. The outcome measures of group differences between times were tested using the Post hoc test (Bonferroni). Multiple linear regression measured the correlation of the intervention. The stepwise method was used to incorporate variables in the regression models. Data were analyzed by SPSS statistical package version 16.0. All analysis used a 95\% confidence interval, and a statistically significant $p$-value of less than 0.05 .

\section{Results}

Study population

Of the 558 patients in the DM Clinic, 177 patients did not meet the inclusion criteria. In total, 381 patients were randomly selected to participate. Of the 192 participants included at baseline (96 intervention and 96 control), 186 (96.8 percent) (93 intervention and 93 control) were eligible for the six-month follow-up. Of the participants in the intervention group, one participant was admitted into the hospital and two participants changed their settlement area. For the control group, two participants changed their health insurance and one participant changed their settlement area (Figure 1).

\section{Baseline characteristics}

Among the 186 participants (93 per group), the majority were female. The age of the intervention and control group participants ranged from 30 to 84 and 33 to 80 years, respectively. All baseline characteristics did not have statistically significant differences between the intervention and the control groups (Table I). 
Figure 1.

Study flowchart
Table I.

Baseline

characteristics

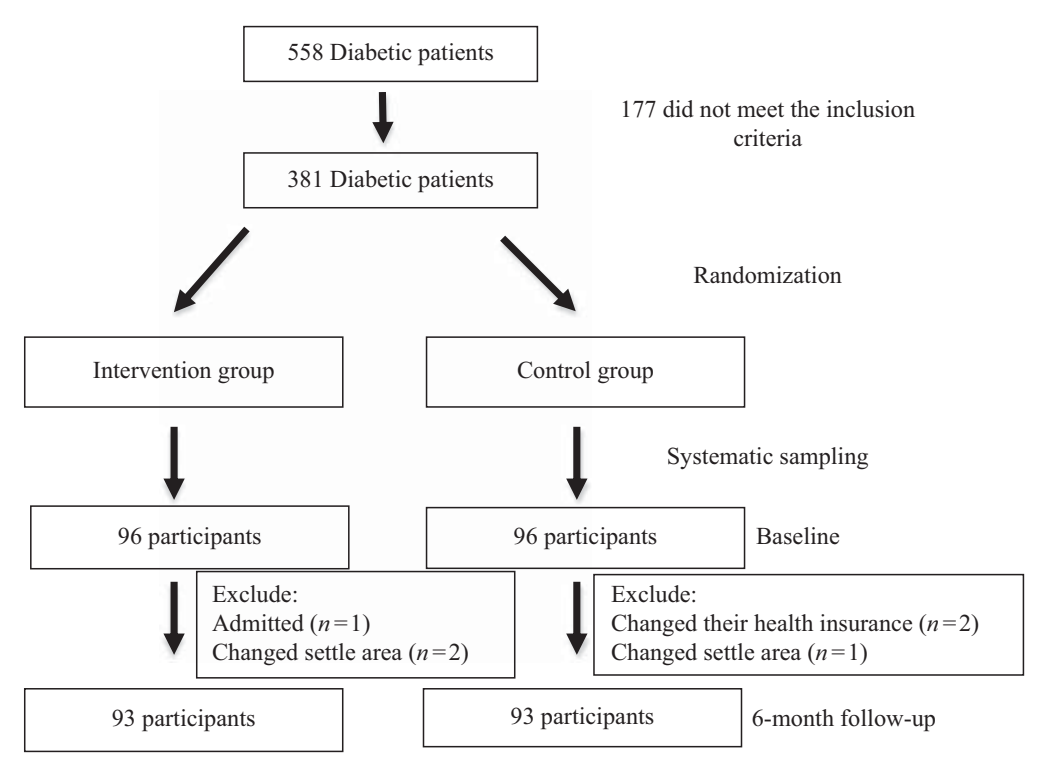

\begin{tabular}{|c|c|c|c|}
\hline Variables & Intervention group $(n=93)(\%)$ & Control group $(n=93)(\%)$ & $p$-value \\
\hline $\begin{array}{l}\text { Gender } \\
\text { Male } \\
\text { Female }\end{array}$ & $\begin{array}{l}25(26.9) \\
68(73.1)\end{array}$ & $\begin{array}{l}37(39.8) \\
56(60.2)\end{array}$ & $0.068^{\mathrm{a}}$ \\
\hline $\begin{array}{l}\text { Age } \\
\text { Mean } \pm \text { SD } \\
\text { Min-max }\end{array}$ & $\begin{array}{c}61.35 \pm 10.17 \\
30-84\end{array}$ & $\begin{array}{c}63.47 \pm 8.99 \\
33-80\end{array}$ & $0.098^{\mathrm{c}}$ \\
\hline $\begin{array}{l}\text { Educational level } \\
\text { Illiterate } \\
\text { Primary school } \\
\text { Secondary school } \\
\text { Vocational school } \\
\text { Bachelor degree }\end{array}$ & $\begin{aligned} & (5.4) \\
56 & (60.2) \\
16 & (17.2) \\
7 & (7.5) \\
9 & (9.7)\end{aligned}$ & $\begin{aligned} & (5.4) \\
65 & (69.9) \\
17 & (18.3) \\
2 & (2.1) \\
4 & (4.3)\end{aligned}$ & $0.228^{\mathrm{b}}$ \\
\hline $\begin{array}{l}B M I\left(k g / m^{2}\right) \\
\text { Mean } \pm \text { SD } \\
\text { Min-max }\end{array}$ & $\begin{array}{c}27.19 \pm 4.84 \\
18.20-41.80\end{array}$ & $\begin{array}{c}26.54 \pm 5.15 \\
15.90-47.80\end{array}$ & $0.899^{c}$ \\
\hline $\begin{array}{l}\text { Health insurance } \\
\text { Universal coverage } \\
\text { Universal coverage (other) } \\
\text { Government/state enterprise officer } \\
\text { No }\end{array}$ & $\begin{aligned} 80 & (86.0) \\
2 & (2.1) \\
7 & (7.5) \\
4 & (4.4)\end{aligned}$ & $\begin{aligned} 83 & (89.2) \\
5 & (5.4) \\
4 & (4.3) \\
1 & (1.1)\end{aligned}$ & $0.195^{\mathrm{b}}$ \\
\hline $\begin{array}{l}\text { Duration of being diabetes (years) } \\
\text { Mean } \pm \text { SD } \\
\text { Min-max }\end{array}$ & $\begin{array}{c}9.78 \pm 7.56 \\
1-40\end{array}$ & $\begin{array}{c}8.43 \pm 5.96 \\
1-33\end{array}$ & $0.087^{\mathrm{c}}$ \\
\hline $\begin{array}{l}\text { Smoking } \\
\text { Never } \\
\text { Ever } \\
\text { Current smoker }\end{array}$ & $\begin{aligned} 85 & (91.4) \\
3 & (3.2) \\
5 & (5.4)\end{aligned}$ & $\begin{aligned} 82 & (88.2) \\
4 & (4.3) \\
7 & (7.5)\end{aligned}$ & $0.798^{\mathrm{b}}$ \\
\hline Notes: $n=186 . p$ by ${ }^{\mathrm{a}} \chi^{2}$ test; ${ }^{\mathrm{b}}$ Fish & er's exact test; ${ }^{c} t$-test. $*$ Statistically & y significant at $p<0.05$ & \\
\hline
\end{tabular}

$56(60.2)$

6 (17.2)

7 (7.5)

9 (9.7)

(18.3)

$2(2.1)$

$26.54 \pm 5.15$

15.90-47.80

$83(89.2)$

5 (5.4)

$4(4.3)$

$2(2.1)$

$4(4.4)$

$.43 \pm 5.96$

$82(88.2)$

$4(4.3)$

$3(3.2)$

7 (7.5)

$0.228^{\mathrm{b}}$

$.899^{c}$

$195^{\mathrm{b}}$

$.087^{\mathrm{c}}$

$.798^{\mathrm{b}}$

Current smoke

Notes: $n=186$. $p$ by ${ }^{\mathrm{a}} \chi^{2}$ test; ${ }^{\mathrm{b}}$ Fisher's exact test; ${ }^{\mathrm{c}} t$-test. $*$ Statistically significant at $p<0.05$ 


\section{Glycemic levels}

The mean of FPG in the intervention group at baseline and the six-month follow-up were $131.81 \pm 29.95$ and $132.24 \pm 28.19 \mathrm{mg} / \mathrm{dL}$, respectively. The mean of FPG in the control group at baseline and the six-month follow-up were $129.34 \pm 25.30$ and $136.04 \pm 25.29 \mathrm{mg} / \mathrm{dL}$, respectively. The mean of $\mathrm{HbA1c}$ in the intervention group at baseline and the six-month follow-up were $8.27 \pm 7.47$ and $6.91 \pm 0.61$ percent, respectively. The mean of HbA1c in the control group at baseline and the six-month follow-up were $7.35 \pm 7.17$ and $7.61 \pm 1.27$ percent, respectively.

FPG and HbA1c were significantly lower in the intervention group when compared to the control group ( $p<0.001$ and $<0.001$, respectively). Within groups at the six-month follow-up, the mean difference of $\mathrm{HbAlc}$ between the intervention and the control groups had a statistically significant difference $(p<0.001)$, whereas the mean difference of FPG between the intervention and the control groups did not have a statistically significant difference $(p=0.334)$ (Table IV). This suggests that HbA1c changed over time depending on the group (Table II).

\section{Periodontal status}

PI, GI, PD and CAL were significantly lower in the intervention group when compared to the control group $(p<0.001,<0.001,<0.001$ and $<0.001$, respectively). Within groups, the difference between baseline and the sixth-month levels of PI, GI, PD and CAL found statistically significant differences in both time and the interaction effect between intervention and time (Table III). At the six-month follow-up, the mean difference of PI, GI, $\mathrm{PD}$ and CAL between the intervention and the control groups had statistically significant differences $(p<0.001,<0.001,0.006$ and 0.021, respectively) (Table IV). This indicates that the index for periodontal status changed over time and depended on the group.

\section{Multiple linear regression analysis}

At the six-month follow-up, the glycemic level and periodontal status were negatively correlated to the intervention group with statistical significance. FPG was significantly

\begin{tabular}{|c|c|c|c|c|c|c|}
\hline Source of variation & SS & $\mathrm{df}$ & MS & $F$ & $p$ & \\
\hline \multicolumn{7}{|l|}{$F P G$} \\
\hline \multicolumn{7}{|l|}{ Between subjects } \\
\hline Intervention & 6,590,952.301 & 1 & 6,590,952.301 & 5.953 & $<0.001 *$ & \\
\hline Within group (error) & $203,709.946$ & 184 & $1,107.119$ & & & \\
\hline \multicolumn{7}{|l|}{ (Between group error) } \\
\hline \multicolumn{7}{|l|}{ Within subjects } \\
\hline Time & 396.387 & 1 & 396.387 & 1.047 & 0.308 & \\
\hline Intervention $\times$ Time & $1,997.430$ & 1 & $1,997.430$ & 5.274 & $0.023 *$ & \\
\hline Intervention $\times$ Within group (error) (within subject error) & $69,690.183$ & 184 & 378.751 & & & \\
\hline \multicolumn{7}{|l|}{$\mathrm{HbAlc}$} \\
\hline Between subjects & & 1 & & & & \\
\hline $\begin{array}{l}\text { Intervention } \\
\text { a }\end{array}$ & $21,134.773$ & 184 & $21,134.773$ & 1.355 & $<0.001^{*}$ & \\
\hline $\begin{array}{l}\text { Within group (error) } \\
\text { (Between group error) }\end{array}$ & $2,869.131$ & & 15.593 & & & \\
\hline \multicolumn{7}{|l|}{ Within subjects } \\
\hline Time & 28.270 & 1 & 28.270 & 2.016 & 0.157 & Table II. \\
\hline Intervention $\times$ Time & 60.282 & 184 & 60.282 & 4.298 & $0.040^{*}$ & Repeated measure \\
\hline Intervention $\times$ Within group (error) (within subject error) & $2,580.529$ & & 14.025 & & & ANOVA of FPG \\
\hline \multicolumn{7}{|l|}{ Notes: $n=186 . *$ Statistically significant at $p<0.05$} \\
\hline
\end{tabular}


Source of variation

PI

Between subjects Intervention

Within group (error) (between group error)

254

Table III.

Repeated measure ANOVA of PI, GI, PD and CAL

Within subjects

Time

Intervention $\times$ Time

GI

Between subjects

Intervention

Within group (error) (between group error)

Within subjects

Time

Intervention $\times$ Time

PD

Between subjects

Intervention

Within group (error) (between group error)

Within subjects

Time

Intervention $\times$ Time

$C A L$

Intervention

Within group (error) (between group error)

Within subjects

Time

Intervention $\times$ Time

Note: $n=186$
Intervention $\times$ Within group (error) (within subject error)

Intervention $\times$ Within group (error) (within subject error)

Intervention $\times$ Within group (error) (within subject error)

Between subjects

Intervention $\times$ Within group (error) (within subject error)

2877.245
$236.513 \quad 184$

$\begin{array}{rr}643.272 & 1 \\ 106.517 & 184\end{array}$

643.272

0.579

$\begin{array}{lllll}25.074 & 1 & 25.074 & 161.401<0.001\end{array}$

$\begin{array}{rrrrr}3.177 & 1 & 3.177 & 20.245 & <0.001\end{array}$

$28.585 \quad 184 \quad 0.155$

correlated to group affiliation, age, and FPG at baseline $\left(R^{2}=0.276, p<0.001\right)$. HbA1c was also significantly correlated to group affiliation and $\mathrm{HbAlc}$ at baseline $\left(R^{2}=0.612\right.$, $p<0.001$ ) (Table V). The PI was significantly correlated to group affiliation, PI at baseline and CAL at baseline $\left(R^{2}=0.428, p<0.001\right)$. The GI was significantly correlated to group affiliation, GI at baseline and CAL at baseline $\left(R^{2}=0.478, p<0.001\right)$. PD was significantly correlated to group affiliation, PD at baseline and CAL at baseline $\left(R^{2}=0.378, p<0.001\right)$. CAL was significantly correlated to group affiliation, PD at baseline and CAL at baseline $\left(R^{2}=0.652, p<0.001\right)$ (Table VI).

\section{Discussion}

The Brief-LCDC Program that incorporated lifestyle modification and oral health care was found to successfully decrease glycemic levels and improve the oral health status of patients with type 2 diabetes as shown at the six-month follow-up.

In order to avoid oral complications, incorporated lifestyle modification and oral health care programs for every age group are essential. An analysis of multiple linear regression found that the Brief-LCDC Program was negatively correlated to glycemic levels (FPG and HbA1c) 


\begin{tabular}{|c|c|c|c|c|c|c|c|c|c|}
\hline \multirow[b]{2}{*}{ Variables } & \multirow[b]{2}{*}{ Time } & \multirow[b]{2}{*}{ Control (i) } & \multirow[b]{2}{*}{ Intervention $(j)$} & \multirow[b]{2}{*}{ Mean difference $(i-j)$} & \multirow[b]{2}{*}{ SE } & \multirow[b]{2}{*}{$p$} & \multicolumn{2}{|c|}{$\begin{array}{l}95 \% \text { confidence }^{\text {interval }} \\
\text { in }^{\mathrm{a}}\end{array}$} & \multirow[t]{2}{*}{$\begin{array}{r}\text { Brief-LCDC } \\
\text { Programs }\end{array}$} \\
\hline & & & & & & & Lower & Upper & \\
\hline \multirow{2}{*}{ FPG } & Baseline & 93 & 93 & -5.462 & 4.066 & 0.181 & -13.484 & 2.560 & \\
\hline & 6th month & 93 & 93 & 3.806 & 3.927 & 0.334 & -3.941 & 11.554 & \\
\hline \multirow[t]{2}{*}{$\mathrm{HbA1c}$} & Baseline & 93 & 93 & -0.917 & 0.785 & 0.244 & -2.465 & 0.631 & \\
\hline & 6th month & 93 & 93 & $0.694 *$ & 0.146 & $<0.001^{*}$ & 0.405 & 0.982 & 255 \\
\hline \multirow[t]{2}{*}{ PI } & Baseline & 93 & 93 & 0.115 & 0.080 & 0.154 & -0.044 & 0.274 & \\
\hline & 6th month & 93 & 93 & $0.440^{*}$ & 0.083 & $<0.001^{*}$ & 0.276 & 0.605 & \\
\hline \multirow[t]{2}{*}{ GI } & Baseline & 93 & 93 & 0.048 & 0.089 & 0.592 & -0.128 & 0.224 & \\
\hline & 6th month & 93 & 93 & $0.418^{*}$ & 0.088 & $<0.001^{*}$ & 0.243 & 0.592 & \\
\hline \multirow[t]{2}{*}{ PD } & Baseline & 93 & 93 & 0.117 & 0.134 & 0.384 & -0.147 & 0.381 & Pairwise comp \\
\hline & 6th month & 93 & 93 & $0.360^{*}$ & 0.130 & $0.006^{*}$ & 0.103 & 0.617 & $\begin{array}{l}\text { of the differ } \\
\text { measurements of }\end{array}$ \\
\hline \multirow[t]{2}{*}{ CAL } & Baseline & 93 & 93 & 0.181 & 0.252 & 0.473 & -0.316 & 0.677 & $\begin{array}{l}\text { measurements or } \\
\text { glvcemic level a }\end{array}$ \\
\hline & 6th month & 93 & 93 & $0.560 *$ & 0.241 & $0.021 *$ & 0.084 & 1.036 & periodontal status in \\
\hline \multicolumn{9}{|c|}{ 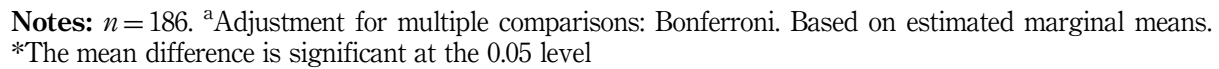 } & $\begin{array}{l}\text { the intervention and } \\
\text { the control groups }\end{array}$ \\
\hline
\end{tabular}

\begin{tabular}{|c|c|c|c|}
\hline Variables & $\begin{array}{l}\text { FPG (6th month) } \\
\text { Paramet }\end{array}$ & $\begin{array}{l}\text { HbA1c (6th month) } \\
\text {, } \text {-value }\end{array}$ & \\
\hline $\begin{array}{l}\text { Group affiliation (ref. control) } \\
\text { Age } \\
\text { FPG at baseline } \\
\text { HbAlc at baseline } \\
\text { Note: } n=186\end{array}$ & $\begin{array}{c}-7.991(3.448), 0.022 \\
-0.390(0.182), 0.034 \\
0.441(0.057),<0.001 \\
R^{2}=0.276, p<0.001\end{array}$ & $\begin{array}{l}0.741(0.043),<0.001 \\
R^{2}=0.612, p<0.001\end{array}$ & $\begin{array}{r}\text { Table V. } \\
\text { Multiple linear } \\
\text { regression analysis for } \\
\text { glycemic level (FPG } \\
\text { and HbAlc) }\end{array}$ \\
\hline
\end{tabular}

and periodontal status (PI, GI, PD and CAL). The Brief-LCDC Program significantly decreased glycemic levels and improved periodontal status when compared to the usual program. Consistent with the LCDC Program which combined lifestyle modification and oral health care by using a common risk factor approach, including individual lifestyle counseling by MI every three months successfully decreased glycemic levels and improved the periodontal status in aging DM patients[20]. A common risk factor approach and a patient-centered approach by MI on the Brief-LCDC Program decreased glycemic levels and improved periodontal status, which was the same as the guideline from the ADA and $\mathrm{EASD}[8]$. The present study found that decreasing the frequency of MI from three months (LCDC Program)[20] and 1 month (face-toface counseling)[26] to six months also decreased glycemic levels and improved periodontal status. However, during the follow-up period of the Brief-LCDC Program, glycemic levels were decreased with statistical significance for HbAlc alone. FPG measured a person's blood sugar level after fasting for at least 8 hours, whereas HbAlc testing also examined hemoglobin levels [24]. The red blood cells had a half-life of about three months, so the HbA1c levels indicated blood sugar levels over this timeframe[24]. This indicates that the results of decreased $\mathrm{HbAlc}$ in the intervention group represented glycemic control behavior of patients for three months, which was better than the FPG.

Decreasing glycemic levels (FPG and HbA1c) following the Brief-LCDC Program were similar to previous studies which found a short-term reduction in FPG after a lifestyle modification program[27], improving blood sugar levels by monthly face-to-face counseling and self-care modification[26, 28], and improving blood sugar levels by an educational 
JHR

256

33,3

Table VI.

Multiple linear

regression analysis for periodontal status $(\mathrm{PI}$, GI, PD and CAL)

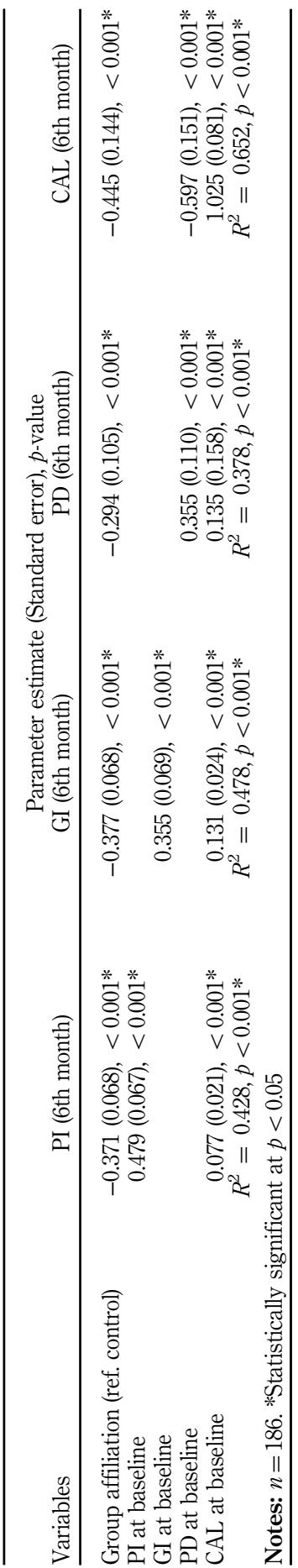


program that reduced resistance to treatment[29]. However, another study found that a three-year program for self-management behavior and single education decreased $\mathrm{HbAlc}$ with no significant difference[13].

Improved periodontal status (PI, GI, PD and CAL) following the Brief-LCDC Program is consistent with results from previous studies[17, 18]. However, a previous study in Thailand found decreasing $\mathrm{HbA1c}$ without a significant difference after periodontal treatment[30]. The severity of periodontal disease influenced the control of $\mathrm{HbA1c}[31,32]$. Another study found that another means of preventing dental complications was the screening for periodontal disease as part of the multidisciplinary management of type 2 diabetes[33].

Introducing a double-blind technique and using biomarkers for assessing the glycemic level and periodontal status, as well as the high response rate (96.8 percent), are strengths of the present study. The selection bias, dependent on compliance and the limited 1-day training for interviewers are the limitations of this study. Future studies need to integrate a long-term follow-up period to assess the effects of intervention, compliance and feasibility over time. The Brief-LCDC Program could be introduced to diabetes clinics in Bangkok to prevent oral complications.

\section{Conclusion}

The Brief-LCDC program has the efficacy to successfully decrease glycemic levels (HbA1c and FPG) and improve the periodontal status (PI, GI, PD and CAL) of patients with type 2 diabetes, if maintained for six months.

\section{References}

1. Albert DA, Ward A, Allweiss P, Graves DT, Knowler WC, Kunzel C, et al. Diabetes and oral disease: implications for health professionals. Ann N Y Acad Sci. 2012; 1255: 1-15. doi: 10.1111/ j.1749-6632.2011.06460.x

2. World Health Organization [WHO]. Global Status Report on Noncommunicable Diseases 2010: description of the global burden of NCDs, their risk factors and determinants. Geneva: WHO; 2011.

3. Rungsin R. An assessment on quality of care among patients diagnosed with type 2 diabetes and hypertension visiting hospitals of Ministry of Public Health and Bangkok Metropolitan Administration in Thailand. Bangkok: National Health Security Office [NHSO]; 2012.

4. National Health Examination Survey Office [NHESO]. The Fifth Thai National Health Examination Survey 2014. Bangkok: NHESO; 2017.

5. Saini R, Saini S, Sugandha RS. Periodontal disease: the sixth complication of diabetes mellitus. J Family Community Med. 2011 Jan-Apr; 18(1): 31. doi:10.4103/1319-1683.78636

6. Bureau of Dental Health, Ministry of Public Health, Thailand. The seventh Thai national oral health survey. 2012 [cited 2013 Jun 18]. Available from: http://dental.anamai.moph.go.th/ oralhealth/PR/E-book/Survey/survey7th.pdf2013

7. Report of Health Department, Bangkok Metropolitan Administration. Prevent and control of non-communicable disease in the health department. Bangkok: Bangkok Metropolitan Administration; 2018.

8. Reusch JED, Manson JE. Management of type 2 diabetes in 2017 getting to goal. JAMA. 2017; 317(10): 1015-6. doi: 10.1001/jama.2017.0241

9. Hettema JE, Steele JM, Miller WR. Motivational interviewing. Ann Rev Clin Psychol. 2005; 1: 91-111. doi: 10.1146/annurev.clinpsy.1.102803.143833

10. Gao X, Lo EC, Kot SC, Chan KC. Motivational interviewing in improving oral health: a systematic review of randomized controlled trials. J Periodontol. 2014 Mar; 85(3): 426-37. doi: 10.1902/ jop.2013.130205 
JHR

33,3

13. Khunti K, Laura JG, Timothy S, Fisher H, Davies MJ. Effectiveness of a diabetes education and selfmanagement programme (DESMOND) for people with newly diagnosed type 2 diabetes mellitus: three-year follow-up of a cluster randomised controlled trial in primary care. BMJ. 2012; 344: e2333. Available from: http://dx.doi.org/10.1136/bmj.e2333

14. Carvalho VF, Okuda OS, Bernardo CC, Pannuti CM, Georgetti MA, De Micheli G, et al. Compliance improvement in periodontal maintenance. J Appl Oral Sci. 2010 May-Jun; 18(3): 215-9.

15. Sun WL, Chen LL, Zhang SZ, Wu YM, Ren YZ, Qin GM. Inflammatory cytokines, adiponectin, insulin resistance and metabolic control after periodontal intervention in patients with type 2 diabetes and chronic periodontitis. Intern Med. 2011; 50(15): 1569-74.

16. Katagiri S, Nitta H, Nagasawa T, Izumi Y, Kanazawa M, Matsuo A, et al. Effect of glycemic control on periodontitis in type 2 diabetic patients with periodontal disease. J Diab Investig. 2013 May; 4(3): $320-5$.

17. Ou L, Li RF. Effect of periodontal treatment on glycosylated hemoglobin levels in elderly patients with periodontal disease and type 2 diabetes. Chin Med J. 2011 Oct; 124(19): 3070-3.

18. Singh SK, Kumar V, Kumar S, Subbappa A. The effect of periodontal therapy on the improvement of glycemic control in patients with type 2 diabetes mellitus: a randomized controlled clinical trial. Int J Diab Dev Ctries. 2008 Apr-Jun; 28(2): 38-44. doi: 10.4103/0973-3930.43097

19. McGrath C, Lawrence HP, Blinkhorn A. Guest editorial on the festschrift "challenges in population oral health for the 21st century". Community Dent Oral Epidemiol. 2012 Oct; 40(S2): 1-4. doi: $10.1111 /$ j.1600-0528.2012.00736.x

20. Saengtipbovorn S, Taneepanichskul S. Effectiveness of lifestyle change plus dental care (LCDC) program in improving glycemic and periodontal status in aging diabetic patients: a cluster randomized controlled trial. J Periodontal. 2015 Apr; 86(4): 507-15. doi: 10.1902/jop.2015.140563

21. Saengtipbovorn S, Taneepanichskul S. Lifestyle change plus dental care (LCDC) program improves knowledge, attitude, and practice (KAP) toward oral health and diabetes mellitus among the elderly with type 2 diabetes. J Med Assoc Thai. 2015 Mar; 98(3): 279-90.

22. Buatong S, Sapapaut S, Jitjarut S. Ageing related to reason method and needs of learning. J Educ. 2015 Mar; 12(1): 6-17.

23. Sunburanuruk A, Sunburanuruk S. Differentiated instruction. J Edu. 2015 Mar; 12(1): 39-48.

24. American Diabetes Association. Diagnosis and classification of diabetes mellitus. Diab Care. 2013 Jan; 36(S1): 67-74. doi:10.2337/dc10-S062

25. Codental. Indices used for periodontal disease assessment. [cited 2018 Aug 30]. Available from: www.codental.uobaghdad.edu.iq/uploads/lectures/3rd $\% 20$ class $\% 20$ community $\% 20$ dentistry/ $3 \% 20 \mathrm{PDD} \% 20$ Indices.pdf

26. Morrison, F, Shubina M, Turchin A. Lifestyle counseling in routine care and long-term glucose, blood pressure, and cholesterol control in patients with diabetes. Diab Care. 2012 Feb; 35(2): 334-41. doi: 10.2337/dc11-1635

27. Drozek D, Diehl H, Nakazawa M, Kostohryz T, Morton D, Shubrook JH. Short-term effectiveness of a lifestyle intervention program for reducing selected chronic disease risk factors in individuals living in rural appalachia: a pilot cohort study. Adv Prev Med. 2014; 2014, 798184. doi: 10.1155/2014/798184

28. Gao J, Wang J, Zheng P, Haardörfer R, Kegler MC, Zhu Y, et al. Effects of self-care, self-efficacy, social support on glycemic control in adults with type 2 diabetes. BMC Fam Pract. 2013 May; 14, 66. doi: $10.1186 / 1471-2296-14-66$ 
29. Valinsky L, Mishali M, Endevelt R, Preiss R, Dopelt K, Heymann AD. Reducing resistance to treatment, through group intervention, improves clinical measurements in patients with type 2 diabetes. BMC Endocr Disord. 2013; 13(1): 61.

30. Promsudthi A, Pimpansri S, Derochanawong C, Kanchanavasita W. The effect of periodontal therapy on uncontrolled type 2 diabetes mellitus in older subjects. Oral Dis. 2005 Sep; 11(5): 293-8.

31. Demmer RT, Desvarieux M, Holtfreter B, Jacobs Jr, Wallaschofski H, Nauck M, et al. Periodontal status and A1C change: longitudinal results from the study of health in Pomerania (SHIP). Diab Care. 2010 May; 33(5): 1037-43. doi: 10.2337/dc09-1778

32. Kim EK, Lee SG, Choi YH, Won KC, Moon JS, Merchant AT, et al. Association between diabetesrelated factors and clinical periodontal parameters in type-2 diabetes mellitus. BMC Oral Health. 2013 Nov; 13: 64. doi: 10.1186/1472-6831-13-64

33. Pumerantz AS, Bissett SM, Dong F, Ochoa C, Wassall RR, Heidi D, et al. Standardized screening for periodontitis as an integral part of multidisciplinary management of adults with type 2 diabetes: an observational cross-sectional study of cohorts in the USA and UK. BMJ Open Diab Res Care. 2017; 5(1): 5e000413. doi: 10.1136/bmjdrc-2017-000413

\section{Corresponding author}

Saruta Saengtipbovorn can be contacted at: saruta79@gmail.com

For instructions on how to order reprints of this article, please visit our website: 